\title{
Implantation of porous acrylic cement in soft tissues: an animal and human biopsy histological study
}

\author{
P.J. van Mullem*, J.M. Vaandrager ${ }^{\dagger}$, J.P.A. Nicolai ${ }^{\ddagger}$ and J.R. de Wijn* \\ *Departments of Oral Histology and Oral Biomaterials, University of Nijmegen, Philips van Leydenlaan 25, 6500 HB Nijmegen. \\ ${ }^{\dagger}$ Department of Plastic Surgery, Erasmus University, Rotterdam and ${ }^{\ddagger}$ Centre for Plastic Surgery, Municipal Hospital, Arnhem, \\ The Netherlands \\ (Received 30 October 1988; revised 10 May 1989; accepted 23 May 1989)
}

\begin{abstract}
Long-term ( 8 and 24 month) reactions of the (hypo) dermis of the guinea pig to solid and porous (50 vol\%) acrylic implants and four human biopsies from porous subcutaneous acrylic implants were studied light microscopically. The solid implants were encapsulated by dense connective tissue. Mobility was evidenced by the loss of 4 out of 36 after 2 yr and was considered the explanation for the occurrence of ectopic cartilage and mineralized material at some solid implants' surfaces after 2 yr. A dense capsule was not evident with the porous implants, instead vascularized collagenous connective tissues penetrated into and filled the pores, thus anchoring the implant to the body. None of these implants, was lost. Notwithstanding the presence of some multinucleated giant cells, scattered inflammatory cells and loosely packed inflammatory foci with both implant materials, the materials were considered well-tolerated by the body. The histology of the human biopsy did not differ significantly from the porous animal implants.
\end{abstract}

Keywords: PMMA, implants, biocompatibility

The concept of anchoring an implant to the host by ingrowth of its tissues into the pores of the implant material has become known as 'porous attachment'. Among the many porous materials that have been proposed, porous acrylic cement occupies an unique place by the possibility of combined mouldability and porosity.

A technique to prepare an in situ curing cement with pores suitable for tissue ingrowth developed in our laboratory ${ }^{1-6}$ consists of dispersing an aqueous gel, based on $\mathrm{Na}$-carboxymethyl cellulose (CMC), through the dough of a traditionally composed acrylic bone cement. When suitable volume fractions of the gel are dispersed, the gel coalesces into a interconnected filament network through the curing material. The gel is readily dissolved in and resorbed by the biological environment, the remaining network of pores in the cured material offering ample opportunity for tissues to grow in. An additional advantage of the gel addition is the large reduction of the notorious temperature peak during the polymerization of acrylic cements. The aqueous gel acts as an efficient heat sink.

In various publications, reporting the evaluation of this cement as an implant material, emphasis has been on general systemic effects ${ }^{3.7}$ applications in and on hard tissues such as the filling of cavities in bone $e^{4-6.8-13}$ or the augmentation of bone contours $4,9,10,14-17$.

Correspondence to Dr P.J. van Mullem.
The general histokinetics of the hard tissue reaction was found to comprise the disappearance of the CMC gel out of the pores, the subsequent invasion of vascularized fibrous connective tissue during the first $7 \mathrm{~d}$ and the gradual approach and initial ingrowth of a hard tissue frontal zone in the 1 or 2 wk following. After $6 w k$, bone ingrowth was substantial in implants in artificial defects, and bone deposition continued both in and around the implant until, after $10-12 \mathrm{wk}$, up to $75 \%$ of the available pore volume was filled $^{11-18}$

When the material was applied on to cranial bone the distance over which the bone had grown into the implant pores appeared to be in the order of $3 \mathrm{~mm}$, after $52 \mathrm{wk}$ in situ. Figure 1 shows a cranial augmentation in monkeys after such a period of time. Based on the favourable findings in these animal experiments, clinical trials were started using the porous cement in craniofacial reconstruction and for the correction of the sternal deformation called pectus excavatum.

The application of augmentations on to bone partially involves the material's contact with soft tissues. In the case of corrective augmentation of pectus excavatum, the implant will become completely surrounded by soft tissues. Therefore, it was felt necessary to extend the histokinetic study in hard tissues with animal experimentation focussed on the reactions of soft tissues to the porous implant.

This paper reports on the outcome of studies conducted 

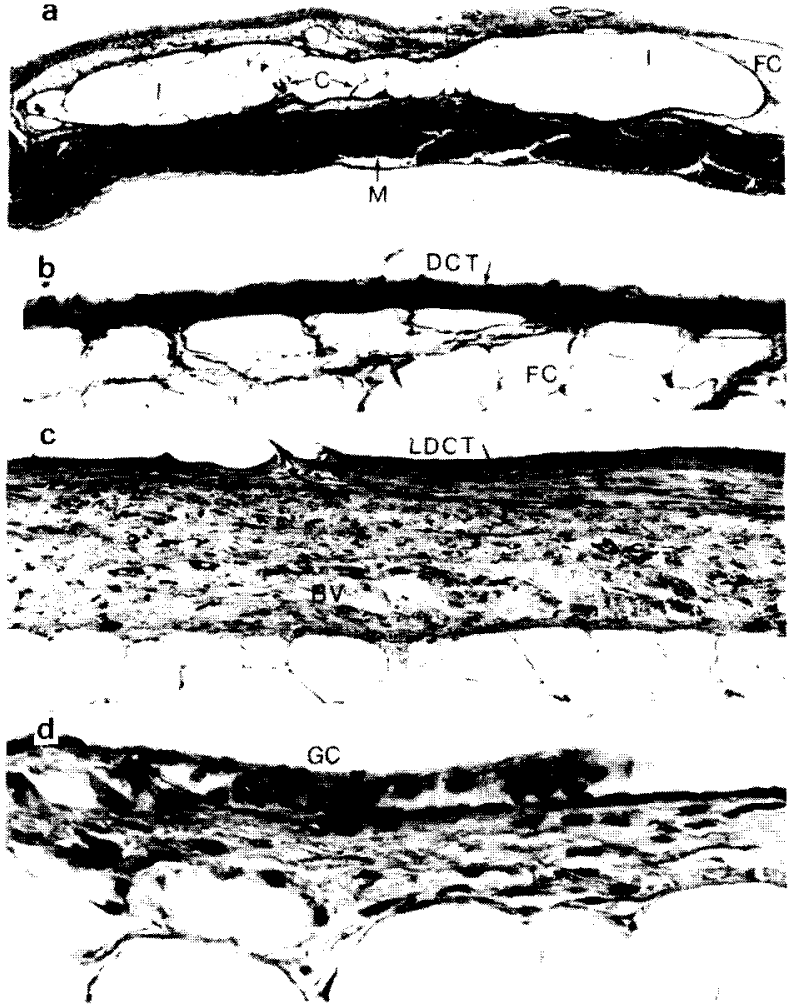

e

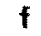$$
\text { e }
$$
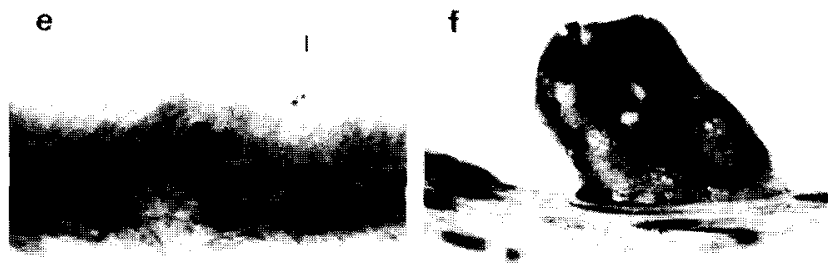

Figure 1 Solid animal implants. (a) General view. HE, original magnification $\times 10 ;(b-d)$ aspects of connective tissue around implants, $H E$, original magnification $\times 140$; (e) collagen fibres of dense connective tissue laver, Mason trichrome, original magnification $\times 560$; $(f)$ multinucleated giant cell in pit in surface of imp/ant material, $H E$, original magnification $\times 560$. l, implant material; $C$, crevice; $M$, muscular tissue; $F C$, fat cells; $D C T$, dense connective tissue; $B \mathrm{~V}$, blood vessel; $L D C T$ less dense connective tissue; GC, multinucleated giant cell.

with solid and porous acrylic implants placed in the hypodermis of guinea pigs. Additionally, biopsies of successful and partially failed pectus excavatum implants were utilized to present some human histological findings.

\section{MATERIALS AND METHODS}

\section{Animal experiment}

A total of 33 outbred white female guinea pigs of the Dunkin-Hartley strain (Central Animal Laboratory, Catholic University, Leuven, Belgium) of average weight $400 \mathrm{~g}$ were used. Implantation was performed by injection of $2 \times 0.5 \mathrm{ml}$ doughy cement into the (hypo) dermis (just above the muscular layer) of the middle of the back of the animals, on either side of the spine. The solid cement was a commercially available bone cement Sulfix $6^{\otimes}$ (Sulzer, Switzerland). The porous cement was prepared by mixing the cement dough (Sulfix 6, without radiopacifier) with 50 vol\% of an aqueous $\mathrm{CMC}$ gel. After curing of the resulting dispersion, the material consisted of interconnected CMC gel-filled 'pores' in an acrylic matrix. The pore volume was $50 \%$ and pore diameters ranged from 300 to $1000 \mu \mathrm{m}$ (Ref. 16). Nineteen animals received solid cement, 14 received porous cement. One animal of the porous group and one of the solid group were killed after 8 month, all others after $2 \mathrm{yr}$. At death, the skin, thorax and abdomen were scrutinized for neoplasms. The implants with surrounding tissue were dissected and fixed in neutral $4 \%$ formaldehyde solution. The tissue pieces were not decalcified. Three pieces which contained epidermis were embedded in JB4 ${ }^{\circledR}$ (Polysciences Inc., Warrington, PA, USA), all others in Paraplast ${ }^{\circledR}$. In the latter case, processing included a stage of exposure to chloroform to dissolve the implant material. Longitudinal sections, $7 \mu \mathrm{m}$ thick, were stained with haematoxylin-toluidin blue-acid fuchsin (JB4), haematoxylin-eosin (HE) and, in appropriate cases, with Masson trichrome, toluidin blue or Perls' Prussian blue method. Moreover, contact microradiographs of selected serial sections were made using a Balteau instrument at $12 \mathrm{kV}$ and $20 \mathrm{~mA}$.

\section{Human biopsy}

From the clinical trials, biopsies of four pectus excavatum augmentations were obtained because reoperation was necessary for the following reasons:

1. After $1 \mathrm{yr}$ the patient, considering the result, asked for a larger augmentation solely for cosmetic reasons.

2. After $1 \mathrm{yr}$ the patient, unsatisfied with the cosmetic result asked for surgery other than the thoracic correction. There were no other complaints or adverse symptoms.

3. After $6 \mathrm{wk}$ the patient was dissatisfied with the implant on vague complaints and required removal. There were no adverse clinical symptoms.

4. After almost 2 yr without complaints a patient demonstrated extrusion of a part of the implant. It appeared that a sharp ridge of the implant had caused a local pressure sore and had started to protrude. From the otherwise successful implant the sharp ridge together with an adhering piece of dermis was removed.

At reoperation the surrounding tissues appeared to have grown into the implants 1,2 and 4, retrieval only being possible by sharp dissection. Implant 3 did not show any ingrowth and, lying loose in the implant bed, could be removed easily. For histological examination the biopsies 1-3 were embedded in Paraplast, sectioned $7 \mu \mathrm{m}$ thick and haematoxylin-eosin stained. Implant 4 was not processed for histological purposes but examined macroscopically.

\section{RESULTS}

Clinically, neoplasms were not found in any of the animals. The following histological description applies to both the 8 month and the $2 \mathrm{yr}$ implants, if not indicated otherwise.

\section{Solid implants}

In the 2 yr group, four animals had lost one of their implants and one implant in another animal protruded through the skin. The 13 remaining animals had retained their two implants.

A representative longitudinal section of an implant with surrounding tissue is shown in Figurc 1a. As the acrylic material was dissolved during processing the implant is represented by free space (I). The implant is located against muscular tissue (M) and is otherwise embedded in connective tissue containing fat cells (Figure 1a, FC). The 
implants are tightly surrounded by a capsule which consists of dense connective tissue (Figure 1b, DCT) where collagen fibre bundles are tightly packed. Locally, a layer of less dense connective tissue (Figure 1c, LDCT) in which the density of packing of fibre bundles is intermediate between dense and loose connective tissue and which contains blood vessels (Figure 1c, BV) is interposed between the capsule and the regular subcutaneous connective tissue. The attachment of the less-dense layer to the capsule is weak as several artificial ruptures, probably due to dissection, were seen between the two. The capsule is directly adjacent to implant (Figure $1 b$ and $c$ ) or is separated locally from it by a layer of multinucleated giant cells (Figure 1d, GC). The fibres and fibre bundles in the capsule appear to run lengthwise in longitudinal sections of the implant; however, at some locations fibres running more or less perpendicularly can be observed (Figure 1e). Multinucleated giant cells are also visible in pits in the implant's surface (Figure $1 f, \mathrm{GC}$ ). Muscle cells, located close to the implants, have a normal appearance. Around most implants some scattered lymphocytes are visible. In one animal in the 2 yr group a loosely packed focus of round cells (Figure $2 a, F$ ) and in another animal a series of densely packed inflammatory cells along the implant were found. Ectopic mineralized material was observed in both implants of three animals. Moreover, one implant in six animals showed this material. In the 8 month animal such material was not found. It was located in the capsule or between the capsule and the implant (Figure 2b, B) and did not contain enclosed cells, nor were active osteoblasts seen at its periphery. Microradiography confirmed it to be mineralized (Figure 2c). As the tissue pieces were not decalcified the material was shattered and partly dislocated. The extent varied from a deposit of $150 \mu \mathrm{m}$ in diameter to a layer covering half implant surface. In one animal, cartilage formation was encountered on the top of both implants. This area stained metachromatically with toluidin blue (Figures $2 d$ and $e$ ).

\section{Porous implants}

Animal specimens. Figure 3a represents part of a section of the 8 month implant. It is surrounded by a layer of connective tissue (LDCT) the density of which is comparable to the less dense connective tissue layer around the capsule of a solid implant. Collagen fibres enter the pores of the implant. The pores of the implant are filled with fibrous connective tissue (CT), occasionally containing some fat cells (FC). Rather frequently $\mathrm{CMC}$ remnants (CMC) can be found in and around the implant.

Where the $2 \mathrm{yr}$ implants are situated against muscular tissue (Figure $3 c, \mathrm{M}$ ) this tissue is of normal appearance (Figure $3 d$ ). The rest of the implants are surrounded by healthy subcutaneous connective tissue, often containing fat cells (Figure $3 b$ ). The tissue directly adjacent to the implant differs from the capsule around solid implants. A dense connective tissue layer, as with the solid implants, is found only occasionally. Instead the tissue is a loose connective tissue. Moreover, collagen fibres of the surrounding tissue are obsenved to enter the pores of the implant. Locally, multinucleated giant cells can be found in pits in the surface of the implant material and at the surface, interposed between the connective tissue and the implant. Inside the implants the pores are filled with well-vascularized connective tissue varying from dense (Figure $3 e, D C T$ ) to extremely loose which contains only a few collagen fibres and much

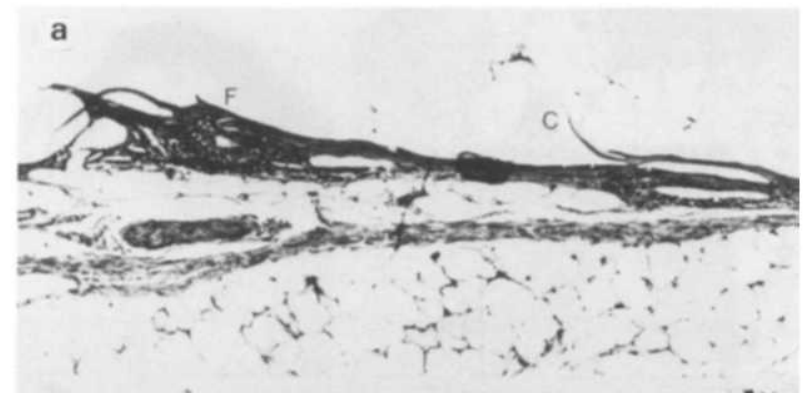

b
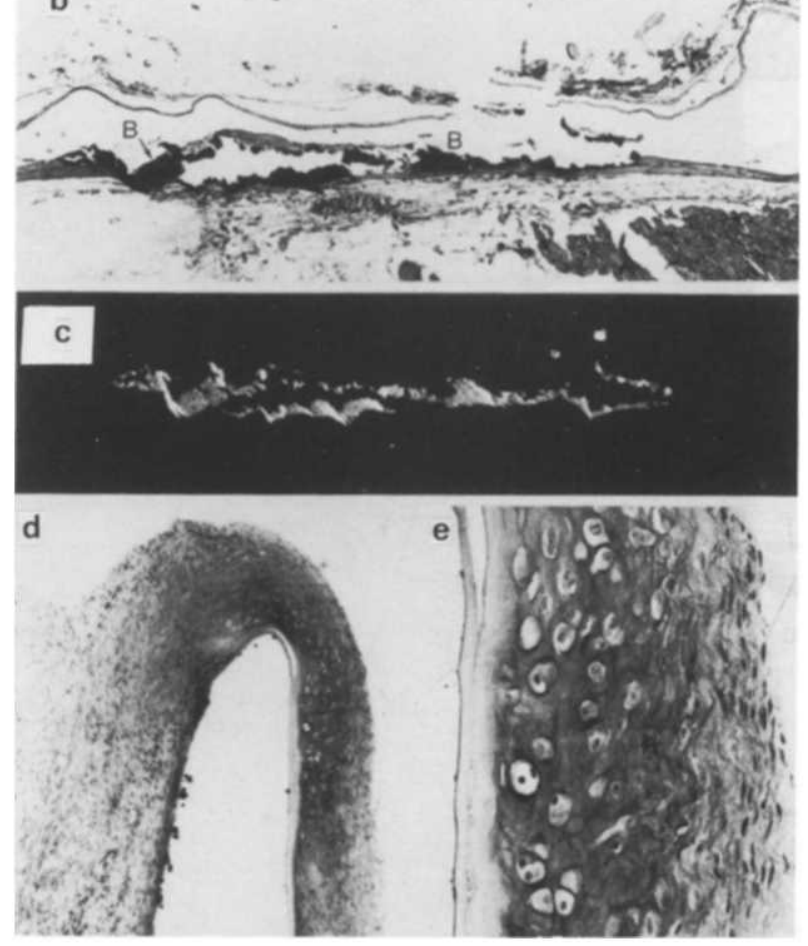

Figure 2 Solid animal implants. (a) Inflammaton focus at surface. HE, original magnification $\times 320 ;(b)$ hard material at surface. $H E$, original magnification $\times 30$; (c) microradiograph of same section as in (b), $H E$, original magnification $\times 30$; (d) top of implant with cartilage formation, toluidin blue, original magnification $\times 55$; (e) detail of (d) toluidin blue, original magnification $\times 255$. F, focus of inflammatory cells; C. crevice; $B$, bone.

amorphous ground substance (Figure $3 e, \mathrm{LC}$ ). The fibres of the dense connective tissue are sometimes observed to end more or less perpendicularly to the implant material or deflect at the surface, as seen at an obliquely cut material surface (Figure $3 f$ ). In a few instances the well-vascularized connective tissue in the pores shows big veins the wall of which can be adjacent to the implant material (Figure 4a). Fat cells can be encountered in the pores in varying amounts: from a few in the entrance of the pores to an overall presence (Figure 3b, FC) which is at the expense of the fibrous connective tissue. Small remnants of $\mathrm{CMC}$ are only occasionally seen. Another rarely seen phenomenon is a brown granular material inter- and intracellularly (Figure $3 e$, $X)$ in haematoxylin-eosin stained sections. It appears to contaın iron, usıng Perls' Prussian blue method. Multınucleated giant cells are found in pits (Figure $3 c, \mathrm{GC}$ ) of the pore surface or locally lining the pore surface (Figure $3 e, \mathrm{GC}$ ). Scattered inflammatory cells and loosely packed foci are found in the pores (Figure $4 b$ ). Plasma cells are rarely seen. No cartilage formation is found in or around the implants. A total of five spots (diameter $150-300 \mu \mathrm{m}$ ) of mineralized material, were encountered in five implants of different animals. Microradiographically the spots appeared to be 


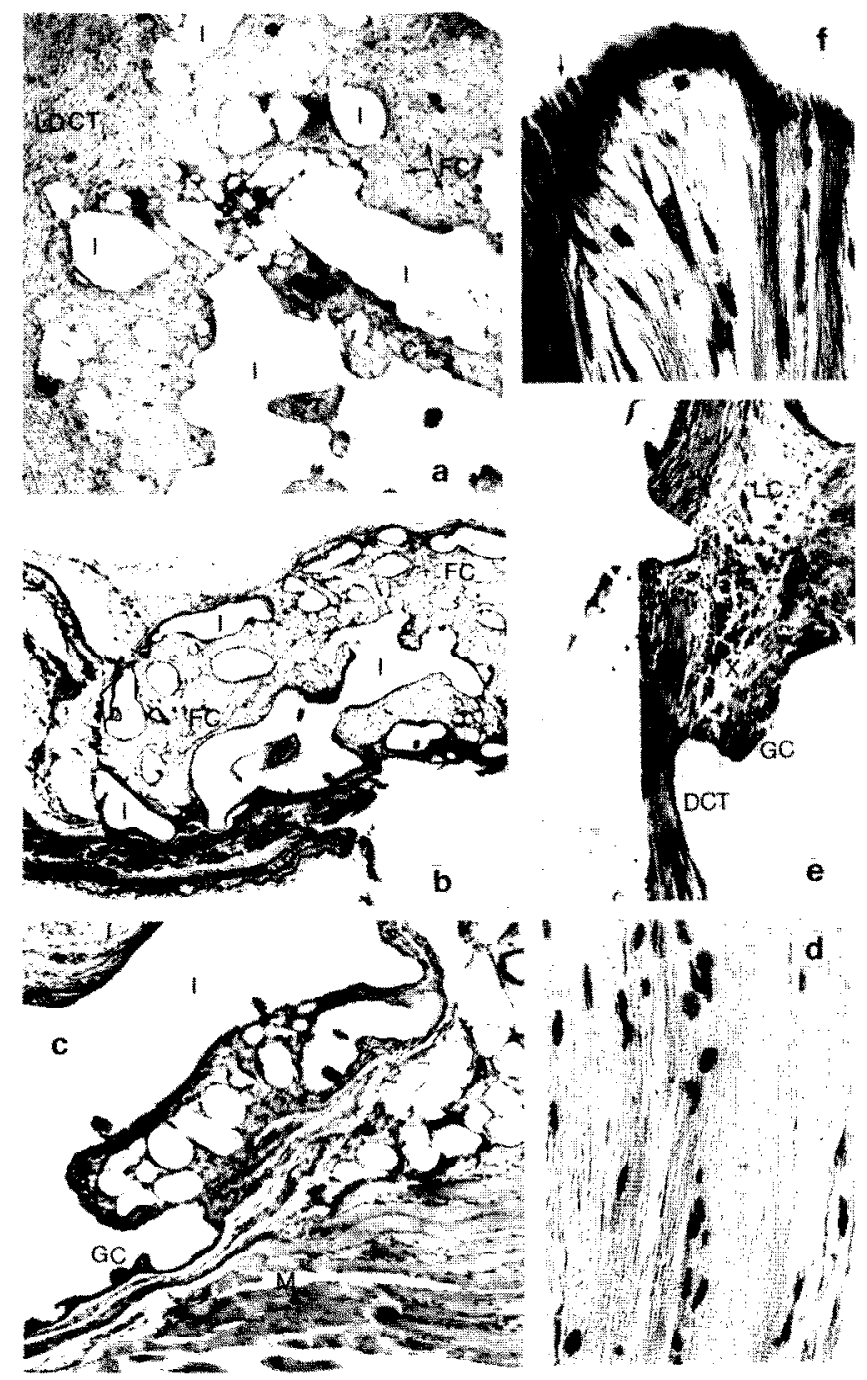

Figure 3 Porous animal implants. (a) General view of 8 month implant, $H E$, original magnification $\times 35 ;(b)$ general view of 2 yr implant. $H E$, original magnification $\times 10 ;(c)$ implant near muscular tissue. $H E$, original magnification $\times 55$; (d) detail of muscie cells, $H E$, original magnification $\times 350$; (e) pore content, HE original magnification $\times 85$; $(f)$ collagen fibres near pore surface, $H E$, original magnification $\times 350$. LDCT, less dense connective tissue; $F C$, fat cel/s: I, implant material; $C T$, connective tissue; $M$, muscular tissue; GC, multinucleated giant cell; DCT, dense connective tissue: $X$ hemosiderin: $L C$, loose connective tissue.

mineralized. They were located in a large pore $(1 x)$, in pits in the pore surface $(3 x)$ and in the outer surface $(1 x)$.

Human biopsy. Figure $5 a$ gives a representative image of the 1 yr human biopsies 1 and 2 . The histology is similar to that of the guinea pig material, however, no fat cells were found in the pores. The soft tissue was well-vascularized, demonstrating scattered inflammatory cells (Figure $5 b, \mathrm{IC}$ ) and several foci of inflammatory cells. Occasionally, CMC remnants (Figure $5 c$ ) were seen. No cartilage or ectopic hard material was found.

Implant 3, however, did not show any tissue ingrowth apart from some necrotic tissue remnants in peripheral crevices. CMC gel residuals were still present deeper in the implant pores. Examination of the pore structure revealed a low pore volume and poorly interconnected small pores.

Macroscopically, the protruding implant 4 showed good adherance to the dermis and the pores were filled with tissue-like structures. A minor inflammatory reaction had

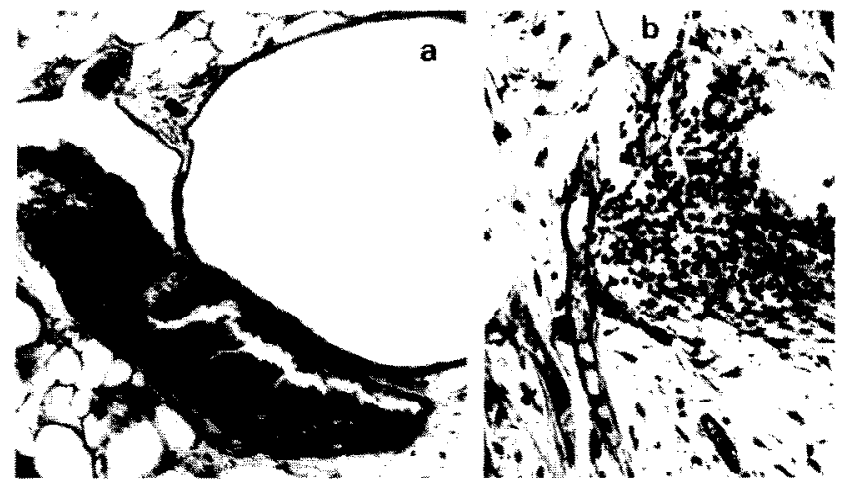

Figure 4 Porous animal implants. (a) Blood lacuna in implant pore. HE, original magnification $\times 190$; (b) loosely packed focus in implant pore, $H E$, original magnification $\times 215$.

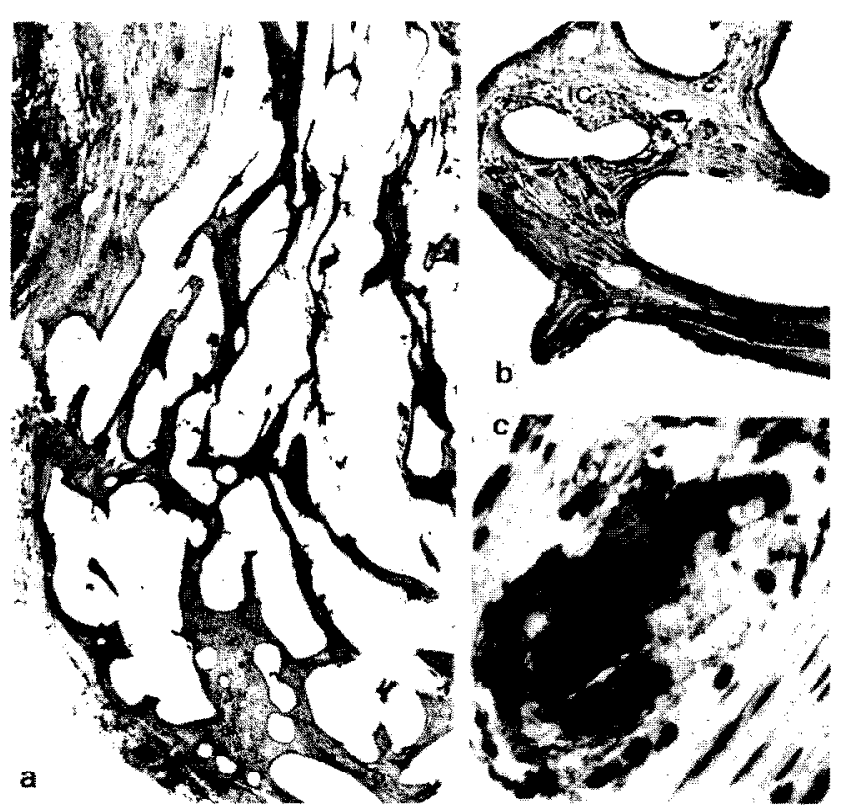

Figure 5 Porous human implant. (a) General view of $1 \mathrm{yr}$ biopsy. $H E$, original magnification $\times 5$; (b) pore with scattered inflammatory cells, $H E$, original magnification $\times 75$; (c) CMC remnant in tissue in pore, $H E$, original magnification $\times 480.1 C$ inflammatory cells.

been present around the protruding part of the material without, however, loosening of the dermis.

\section{DISCUSSION}

The solid implants were generally encapsulated by healthy dense connective tissue. In and around the porous implants, including the human biopsy, a well-vascularized less dense or loose collagenous connective tissue was found. Hence, a true capsule around porous implants was not evident. As capsule thickness has been related to mobility of the implant relative to the surrounding tissue ${ }^{8}$, the present observations can be considered an indication for mobility of the solid implants and for immobility of the porous ones. Inside the pores where fibres may run in close contact with the acrylic surface, the fibrous tissue is replaced, to a varying extend, by fat cells in the $2 \mathrm{yr}$ implants in animals. This indicates a return to a histology which is normal for this location. Although the presence of multinucleated giant cells is suggestive of degradation of the adjacent material, no signs of degradation of the PMMA are observed. It would, however, be surprising, if no multinucleated giant cells were 
present: the implant is a foreign body by its mere physical presence and/or its chemical constitution. Giant cells surrounding $\mathrm{CMC}$ remnants occur in decreasing frequency with time. Also remnants of possibly low carboxylated and therefore less soluble cellulose are found more often in and around the 8 month than in the $2 \mathrm{yr}$ implants. Other reactions to the $\mathrm{CMC}$ are not observed. The brown granular material containing iron occasionally seen can be considered hemosiderin, possibly originating from a bleeding subsequent to the introduction of the implant into the dermis.

The histology of the biopsies 1 and 2 did not differ from that of the guinea pig material and from what can be expected from a successful implant of this type. This corroborates the favourable clinical findings with porous acrylic pectus excavatum augmentations ${ }^{10}$ for periods up to $5 \mathrm{yr}$. The failure of biopsy 3 can be ascribed to a technical factor. The finding of a low pore volume and poor interconnections raised the suspicion that the cement had been incorrectly prepared and probably the third component, water, had been added in too low a quantity. I he part failure of biopsy 4 can be ascribed to another technical factor, i.e. incorrect implant geometry.

Foci and scattered inflammatory cells are found more frequently in and around the porous implants, including the human biopsies, than around the solid implants. The degree of inflammatory reaction, however, does not seem to be deleterious in the sense of being destructive or progressive. In previous studies ${ }^{6,8-15,17}$ where the same porous implant material was placed on to the os parietale of monkeys or in spongeous bone of swine the soft tissue which had grown into the pores showed essentially the same histology. It is concluded that-inflammatory reaction being mild and stationary or subsiding - the porous material is well-tolerated by the animal and human body.

A significant difference between the solid and porous implants appears to be their mobility in the subcutaneous tissue. The mobility of the solid implants is evidenced by the observation in the tissue sections of (albeit artificial) disruptions at the boundary between the capsule and the less dense connective tissue layer, by the lost implants and by the presence of a capsule. Four implants of a total of 36 in the 18 animals with 2 yr solid implants were completely lost. a fifth implant was on its way through the skin. As essentially no inflammatory reactions are associated with the latter implant, a mechanical cause is thought to be responsible for the protrusion of the implant and the loss of the others. Shifting of the implant in the skin caused by movement of the trunk, contact of the animals mutually or with the cage can lead to penetration through the skin. This is in contrast to the 12 animals with 24 implants in the porous group where. over the same period, no implants were lost. Here, collagen fibres and fibre bundles entered the implants and seemed to follow an intricate course in the pores, thus anchoring the implant to the animal's body.

The greater mobility of the solid implants can also explain the observation of ectopic mineralized material around some of these implants. Ten animals which belonged to the solid implant group of $18(2 \mathrm{yr})$ animals, demonstrated hard material at the implant surface. Mobility provokes slight but frequent irritation of the connective tissue and can lead to ectopic hard material formation, just as the so-called Exerzier-knochen' ${ }^{19}$ which is also a result of force acting upon the connective tissue moiety of muscles. In that case the hard material formation is not due to the chemical composition of the material. In addition to the mineralized material around solid implants such material was also formed (albeit in inconspicuous spots) in the pores of 5 of the 24 porous implants in the $2 \mathrm{yr}$ implant animals. Since movement of the implant relative to the tissue is unlikely in the pores, some chemical factor is suspected. With the porous implants the small quantities of mineralized material are considered an acceptable tissue reaction. This is in contrast to the cartilage formation and the frequent formation of mineralized material at the surface of solid implant, observed after $2 \mathrm{yr}$ in this study, which is considered an unacceptable reaction.

Thus, when (in clinical trials) implantation of acrylıc cement in soft connective tissue is foreseen, porous cement seems to be preferable to solid cement. This is because in the present animal and biopsy study it was shown to be anchored to the body by ingrowth of healthy collagenous connective tissue thus avoiding displacement of the implant or even ectopic hard material deposition. The porous cement was also shown, in accordance with previous studies in bony environments, to be well-tolerated by the body.

\section{ACKNOWLEDGEMENTS}

The authors thank Mr J.B. Spaan and Mr H.J. Janssen of the Central Animal Laboratory and Miss Pia Helmich and $\mathrm{Mr}$ S.J.A.M. Nottet of the Department of Oral Histology for their valuable assistance.

\section{REFERENCES}

1 de Wijn, J.R., Poly (methyl methacrylate) -- aqueous phase blends in situ curing porous materials, J Biomed. Mater. Res. Symp. 1976 7.625-635

2 de Wijn. J.R. van Mullem, P.J. and Husiskes, R. Mer.hanical properties of bone porous acrylic implant constructions as a function of healing time, Trans. 13th Int. Biomaterials Symp. 1981, IV, 6

3 de Wiin. J.R., van Mullem, P.J. Slooff, T.J.eral. Residual monomer in in situ curing porous acrylic resin; laboratory evaluation and animal experimentation, in Clinical App/ications of Biomaterials. Advances in Biomaterials, Vol. 4 (Eds A.J.C. Lee, T. Albrechtson and P. I. Branemark) Wiley, New York, 1982, pp 69-76

4 de Wijn, J.R., Porous polymethylmethacrylate cement, development and evaluation of a potential implant material. Thesis, Nijmegen, 1982

5 Ypma, J., de Wijn, J.R., Huiskes, R. et al. Strength and ingrowth aspects of porous acrylic bone cement, Trans. 11 th $\mathrm{ht}$. Biomaterials Symp. 1979, III, 90

6 Ypma, J.F.A.M., Strength and ingrowth aspects of porous acrylic bone cemert, Thesis, Nijmegen, 1981

7 van Mullem, P.J. de Wijn, J.R and Ramselaar, M.M.A. Cell mediated immune reactions to solid and porous PMMA implants in guinea pigs. in Clinical Applications of Biomaterials. Advances in Biomaterials, Vol. 4 (Eds A.J.C. Lee, T. Albrechtson and P -I. Branemark) New York. Wiley, 1982, pp 77-84

8 van Mullem, P.J., de Wijn, J.R. and de Kanter, R., Tissue reaction to PMMA aqueous phase blends; a porous implant material, Meeting of the Europcan Society for Biomateria/s, Brussels, 1978, p 32 (abstract)

9 van Mullem, P.J., Vaandrager, J.M. and de Wijn, J.R., Tissue reaction to porous PMMA implants and augmentations, First World Biomaterials Congress, Baden, 1980, No. 3.8 .4 (abstract)

10 van Mullem, P.J., Vaandrager, J.M., Nicolai, J.P.A. et al., Corrective surgery of cranial and thoracic deformities using porous PMMA. cement; clinical trials and histology of biopsies, Trans. 17 th int. Biomaterials Symp. 1985. VIII, 126

11 van Mullem. P.J. and de Wijn. J.R. Bone and soft connective tissue response to porous acrylic implants. A histokinetic study, J. CranioMaxillo-Facial Surg. 1988, 16, 99-110

12 Ramselaar, M., van Mullem, P.J. and de Wijn, J.R., Tissue reactions to porous PMMA tooth root replacements, First World Biomaterials Congress, Baden, 1980, No.P. 1.47 (abstract)

13 Ramselaar, M.M.A., van Mullem, P.J. and de Wijn, J.f., Porous PMMA tooth root replacements: reactions of the surrounding tissues, $J$. Dent. 1986, 14, 202-208 
14 van Mullem, P.J., Vaandrager, J.M. and de Wijn, J.R., Hard and soft tissue ingrowth into porous acrylic cement, used as augmentation material in monkeys, Trans. 13th Int. Biomaterials Symp. 1981, IV. 112

15 Vaandrager, J.M., van Mullem, P.J. and de Wijn, J.R., Application of porous acrylic cement in cranial augmentations and defects; animal experiments and clinical trial, First World Biomaterials Congress, Baden, 1980, No. P. 1.39 (abstract)

16 Vaandrager, J.M., van Mullem, P.J. and de Wijn, J.R., Porous acrylic cement for correction of craniofacial deformities and repair of defects, animal experimentation and two years of clinical application, Biomaterials 1983, 4, 128-130

17 Vaandrager, J.M., van der Meulen, J.C.H., de Wijn, J.R. et al., Craniofacial contouring and pectus excavatum correction by porous acrylic: four years of clinical application, in Trans. VIII Int. Congress Plastic and Reconstructive Surgery (Ed. H.B. Williams), Montreal, 1983, p 656-657

18 Groenenberg, W.H., Botingroei in poreuze kunststof, Thesis, Groningen, 1984

19 Hueck, W., Morphologische Pathologie, G. Thieme, Leipzig, 1937 